\title{
A 'minor' fracture of the femoral neck
}

\author{
S. S. WALSH \& W. J. ROBSON
}

Accident and Emergency Department, Royal Liverpool Children's Hospital, Liverpool, England

\section{INTRODUCTION}

Fractures of the neck of the femur in childhood are rare. They occur 130-200 times less frequently than in adults and represent $2 \%$ of all femoral fractures in children (Quinlan et al,. 1979). This fracture is caused by considerable force and male adolescents are more prone to this injury (Cheng et al. 1975). The present authors report a case of a subtle fracture of a femoral neck following minor trauma in a child.

\section{CASE REPORT}

An 8-year-old boy presented to the Accident and Emergency Department of the Royal Liverpool Children's Hospital, Liverpool, England, complaining of left hip pain of one day's duration. He gave a history of two episodes of trauma on the preceding day. Firstly, he had fallen on hard, level ground whilst running. Later that day, a sibling had kicked him in the left groin. Although he had some discomfort after both injuries, he had not experienced pain until the day of presentation. There was no associated limp.

Clinical examination revealed a tender, 2 -cm diameter haematoma overlying the left iliac crest. Gait and all movements of the left hip were normal. An X-ray of the pelvis and hip joints was performed and reported as normal by the casualty officer. The child was allowed home with no specific treatment.

The radiologist reported evidence of a crack in the distal cortex of the left femoral neck consistent with a fracture (Fig. 1). Therefore, the patient was recalled and reattended within $48 \mathrm{~h}$ of the initial visit. An orthopaedic doctor confirmed the original clinical findings. The child was admitted to hospital for bed rest and further investigation. Within the first week of admission, the patient had tomography of the left femoral neck (Fig. 2), which confirmed the fracture, and an isotope bone scan, which was normal.

Correspondence: $\operatorname{Dr}$ S. S. Walsh, Registrar, Accident and Emergency Department, Royal Liverpool Children's Hospital (Alder Hey), Eaton Road, Liverpool L12 2AP, England 
(a)

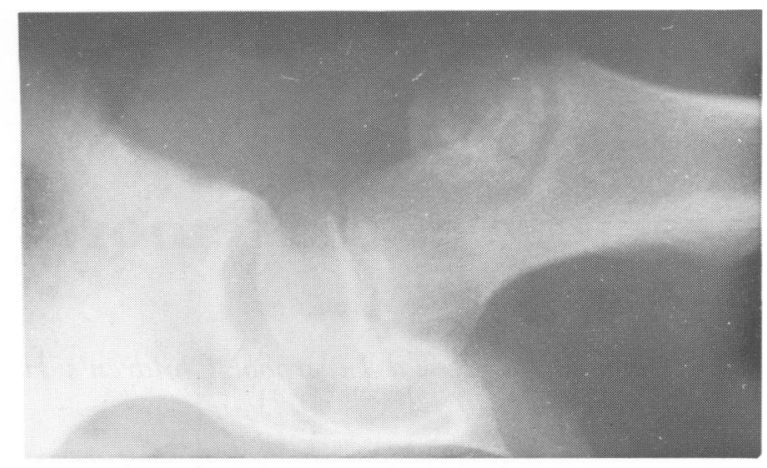

(b)

Fig. 1 (a) (b) Comparison view of right femoral neck.

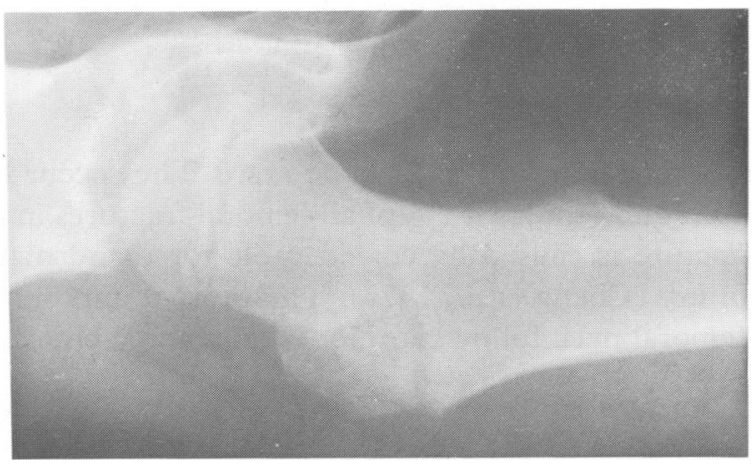

(a) X-ray demonstrating a crack in the distal cortex of the left femoral neck consistent with acte

Fig. 2 Tomography of the left femoral neck confirming the fracture.

The child was non weight bearing on the left leg for a total of 2 months. An X-ray at this time demonstrated healing of the fracture (Fig. 3). He was on partial weight bearing for a further 2 months and on full weight bearing thereafter. 


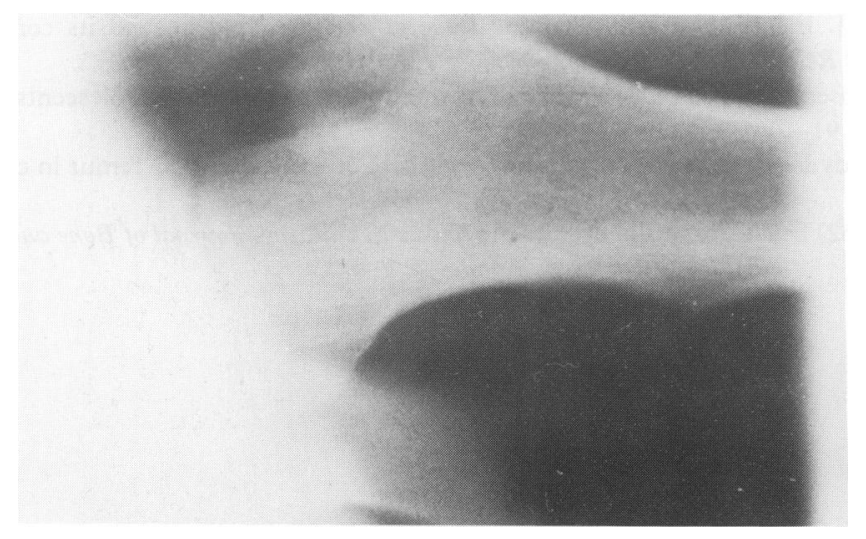

Fig. $3 \mathrm{X}$-ray demonstrating the healing of the fracture.

\section{DISCUSSION}

This case report highlights a number of unusual aspects including the minor degree of trauma, the lack of relevant clinical signs and the subtle X-ray changes.

Although femoral fractures are normally associated with severe trauma, particularly road traffic accidents and falls from heights, $10 \%$ of patients in some studies sustained their fractures from minor trauma (Canale \& Bourland, 1977). The correct diagnosis was made in $95 \%$ of reported cases at admission (Ratliff, 1962). Lack of clinical abnormality with a normal initial X-ray was alluded to by another author (Kay \& Hall, 1971).

The main concern with any femoral neck fracture is the high complication rate. These included avascular necrosis, non-union, coxa vara and premature closure of the proximal growth plate. The important prognostic factors include the amount of damage to the vascularization (Pforringer $\&$ Rosemeyer, 1980) and the degree of displacement of the fracture at the time of injury (Cheng et al., 1975).

Treatment of femoral fractures is, in general, still a contentious issue but few would disagree with the non-operative management adopted here. In non-displaced fractures in three large series, there was a high percentage of good results no matter what treatment was followed (Canale \& Bourland, 1977). Finally, the case demonstrates the importance of a radiologist reporting all $\mathrm{X}$-rays.

\section{REFERENCES}

Canale S. T. \& Bourland W. L. (1977) Fracture of the neck and intertrochanteric region of the femur in children. Fournal of Bone and foint Surgery 59A, 431-43.

Cheng K. C., Chaca P. B. \& Lee B. T. (1975) Fractures of the neck of the femur in childhood and adolescence. Injury 7, 111-19. 
Kay S. P. \& Hall J. E. (1971) Fracture of the femoral neck in children and its complications. Clinical $\frac{\mathbb{\Phi}}{\varrho}$ Orthopaedics and Related Research 80, 53-60.

Pforringer W. \& Rosemeyer B. (1980) Fractures of the hip in children and adolescents. Acta Orthopaedica $\frac{3}{\mathbb{2}}$ Scandinavica 51, 91-108.

Quinlan W. R., Brady P. G. \& Regan B. F. (1979) Fracture of the neck of the femur in childhood. Injury 11, $\overrightarrow{\vec{F}}$

242-7.
Ratliff A. H. C. (1962) Fractures of the neck of the femur in children. fournal of Bone and foint Surgery 44B, 528-42. 